\title{
Efficacy of Naftopidil as a Medical Expulsive Therapy in Japanese Men With Ureteral Stones: A Prospective Randomized Controlled Study
}

\author{
Kenji Ohgaki
}

\begin{abstract}
Background: Naftopidil combined with an antispasmodic agent and a supplement that facilitates stone expulsion has reportedly produced an increased rate of ureteral stone expulsion. A randomized controlled study was conducted to determine the efficacy of naftopidil as a medical expulsive therapy for male patients with ureteral stones.
\end{abstract}

Methods: Male patients $(n=500)$ with stones from the upper to the lower ureter were randomized to one of four groups and followed for 1 month to assess spontaneous passage of stones. The control group received only analgesics. The other three groups received daily doses of $240 \mathrm{mg}$ flopropione, an antispasmodic agent and 1,350 mg extract of Quercus salicina Blume/Quercus stenophylla Makino (QS), a supplement that facilitates stone expulsion; $50 \mathrm{mg}$ naftopidil; or $50 \mathrm{mg}$ naftopidil in combination with $240 \mathrm{mg}$ flopropione and 1,350 mg QS. Stone expulsion and characteristics were evaluated by urinalysis; kidney, ureter and bladder X-ray; ultrasound; and computed tomography.

Results: The probability of expulsion of ureteral stones $<6 \mathrm{~mm}$ increased 1.570-fold (95\% confidence interval (CI): $1.039-2.374, \mathrm{P}<$ $0.05)$ with naftopidil compared to control; the probability of expulsion of a lower ureteral stone $<6 \mathrm{~mm}$ increased 1.778 -fold $(95 \% \mathrm{CI}$ : $1.066-2.965, \mathrm{P}<0.05)$ with naftopidil compared to control. None of the stones $>6 \mathrm{~mm}$ spontaneously passed.

Conclusions: For relatively small ureteral stones $<6 \mathrm{~mm}$, analgesic treatment combined with naftopidil would be the first choice. However, for relatively large ureteral stones $>6 \mathrm{~mm}$, it appears that analgesia is sufficient for initial treatment of ureteral stone.

Keywords: Naftopidil; Ureteral stone; Medical expulsive therapy

Manuscript submitted April 27, 2019, accepted May 13, 2019

Department of Urology, Asao General Hospital, 6 Chome-25-1 Kamiasao Asao Ward, Kawasaki, Kanagawa 215-0021, Japan.

Email: kogaki2018@gmail.com

doi: https://doi.org/10.14740/jocmr3843

\section{Introduction}

Ureteral stones are common. The annual disease rate of upper urinary tract stones was 137.9 per 100,000 population according to an epidemiological investigation of urinary calculus conducted in Japan in 2015, which is an approximately threefold increase over that reported in an investigation in 1965 [1]. Most patients with ureteral stones visit hospitals due to renal colic. Non-steroidal anti-inflammatory drugs (NSAIDs) and non-narcotic pain-relievers are administrated. The pain is often controlled within several hours, but placement of indwelling ureteral stents may be urgently indicated when severe pain continues. When the spontaneous passage of ureteral stones is expected, patients are advised to maintain a high water intake, and spasmolytic drugs and drugs facilitating stone expulsion are often prescribed.

It has been recently reported that $\alpha 1$-blockers facilitate ureteral stone expulsion [2]. The stimulation of $\alpha 1$-adrenergic receptors increases ureteral peristaltic frequency, smooth muscle tonus and contractile force, resulting in ureteral spasm and decreased ureteral flow [3]. The $\alpha 1$-adrenergic receptor consists of three subtypes: $\alpha 1 \mathrm{~A}-, \alpha 1 \mathrm{~B}-$ and $\alpha 1 \mathrm{D}$-adrenergic receptors. It is thought that $\alpha 1 \mathrm{~A}$-adrenergic receptors are widespread in the proximal urethra, prostate and bladder outflow. The $\alpha 1 \mathrm{~B}$-adrenergic receptors are found more often in the vascular smooth muscles, and $\alpha 1 \mathrm{D}$-adrenergic receptors are predominantly found in the detrusor. Therefore, $\alpha 1 \mathrm{~A}$ - and a1D-blockers were originally used for the treatment of lower urinary tract symptoms associated with benign prostatic hyperplasia and neurogenic bladder. Further, the existence of $\alpha 1$ receptors has been demonstrated in the human ureter. While $\alpha 1 \mathrm{~A}-, \alpha 1 \mathrm{~B}-$ and $\alpha 1 \mathrm{D}-$ receptors exist in the ureter, the $\alpha 1 \mathrm{D}-$ receptor is widely distributed from the proximal to distal ends. Higher expression of $\alpha 1 \mathrm{~A}-, \alpha 1 \mathrm{~B}-$ and $\alpha 1 \mathrm{D}-$ receptors has been demonstrated in the distal ureter than the proximal ureter $[4$, 5].

Some reports have described the effectiveness of naftopidil for ureteral stone expulsion [6-11]. When various $\alpha 1$-blockers, such as urapidil, tamsulosin and naftopidil, were administered to patients with ureteral stones to determine their efficacy for stone expulsion, naftopidil in combination with an antispasmodic agent and a supplement that facilitates stone expulsion produced a significantly increased rate of ureteral stone expulsion [12]. However, one study reported that naftopidil did not 
increase spontaneous stone passage rates or reduce analgesic use [13]. This prospective, multicenter, randomized controlled study was therefore designed to clarify the effect of naftopidil for medical expulsive therapy (MET), including the factors of stone size and position.

\section{Materials and Methods}

Patient databases from Nippon Medical School Musashi Kosugi Hospital, Ookurayama Memorial Hospital, Minami Machida Hospital, Kitamurayama Hospital and Asao General Hospital were analyzed. From July 2007 to December 2017, 500 patients with a unilateral ureteral stone $<10 \mathrm{~mm}$ in size were enrolled; 335 patients completed the study. All patients were diagnosed as having ureteral stones by urinalysis; ultrasonography; and kidney, ureter and bladder X-ray (KUB). Non-contrast computed tomography (CT) or drip infusion pyelography (DIP) was performed when necessary. The ureteral stones were classified as upper ureteral (U1), medial ureteral (U2) and lower ureteral (U3). U1 was defined as a stone located below the ureteropelvic junction to the upper border of the iliac crest. U2 was defined as a stone overlapping the ilium. U3 was defined as a stone located below the lower border of the sacroiliac joint to the ureterovesical junction. The exclusion criteria included multiple stones, severe hydronephrosis, urinary tract infection, a history of ureteral surgery, renal colic more than $24 \mathrm{~h}$ in duration, diabetes mellitus, hypotension, previous spontaneous stone expulsion and a history of intake of an $\alpha$-adrenergic blocker or calcium antagonist. The study was performed in accordance with the Declaration of Helsinki and approved by the local ethics committee.

The 500 patients were placed randomly into one of four groups of 125 patients each. Patients in group A were given analgesics as required. Patients in group B were given 240 $\mathrm{mg}$ flopropione and 1,350 mg extract of Quercus salicina Blume/Quercus stenophylla Makino (QS) once daily. Patients in group $\mathrm{C}$ were given $50 \mathrm{mg}$ naftopidil once daily. Patients in group D were given $240 \mathrm{mg}$ flopropione, 1,350 mg QS extract and $50 \mathrm{mg}$ naftopidil once daily. A total of 335 patients completed this study. All patients were told to drink at least 2 L of water daily. The four groups were followed for 30 days. Urinalysis, KUB and ultrasonography were performed on days 1,14 , and 28. NSAIDs were administered to control the onset of acute renal colic. Medication side effects were carefully documented during the treatment period.

Discrete variables are presented as counts or frequencies and were evaluated by the Chi-square or Fisher's exact test. Skewed data are summarized as the median and interquartile range (IQR), and were analyzed with the Mann-Whitney $U$ test. The Cox proportional hazards regression model was applied to estimate the effects of different variables on stone expulsion. The statistical software "EZR" (Easy R) was used for all analyses [14]. All statistical tests were based on two-tailed probability with $\mathrm{P}<0.05$ considered statistically significant. The sample size was sufficient to achieve a statistical power of $95 \%$ at $5 \%$ type I error.

\section{Results}

Table 1 shows the patient characteristics. A total of 335 patients completed the study; 38 patients in group A, 39 patients in group $\mathrm{B}, 44$ patients in group $\mathrm{C}$ and 44 patients in group $\mathrm{D}$ were lost to follow-up or arbitrarily withdrew. Medication side effects appeared in five patients. Extracorporeal shock-wave lithotripsy was performed in 54 patients, and 24 patients received indwelling ureteral stents due to pyelonephritis and pain. Transfer to the hospital occurred in four patients and four patients withdrew due to treatment of other diseases. The average patient ages in the control; flopropione and QS extract; naftopidil, flopropione and QS extract; and naftopidil groups were 48.3, 45.7, 48.8 and 45.9 years old, respectively, and the average stone sizes were $5.1,5.1,5.1$ and $4.9 \mathrm{~mm}$, respectively. There were no significant differences in age, stone size, or stone position among the groups (Table 1). In all cases, the mean expulsion times for each group were 20.0, 22.6, 16.8 and 17.8 days, respectively. In all U1 cases, the mean expulsion times for each group were 23.5, $25.2,20.1$ and 19.5 days, respectively. In all U2 cases, the mean expulsion times for each group were 27.3, 24.0, 24.2 and 23.3 days, respectively. In all U3 cases, the mean expulsion times for each group were $17.4,19.5,13.4$ and 16.0 days, respectively. There were no significant differences between U1 and U2 cases. There were significant differences between groups $\mathrm{A}$ and $\mathrm{C}$ in all cases and in all $\mathrm{U} 3$ cases $(\mathrm{P}<0.05)$.

In all cases, multivariate analysis with a Cox proportional hazards model indicated that the probability of expulsion was 0.638 times higher (95\% confidence interval (CI): 0.429 $-0.948)$ in group $\mathrm{B}$ than in group $\mathrm{A}(\mathrm{P}<0.05)$, and 1.426 times higher (95\% CI: $1.000-2.033)$ in group $\mathrm{C}$ than in group $\mathrm{A}(\mathrm{P}$ $<0.05$ ), while group D compared with group A did not demonstrate an increased probability of expulsion. In U3 cases, the probability of expulsion was 1.555 times higher $(95 \% \mathrm{CI}$ : $1.013-2.388)$ in group $\mathrm{C}$ than in group $\mathrm{A}(\mathrm{P}<0.05)$, while the other groups compared with group A did not demonstrate an increased probability of expulsion. Naftopidil in combination with an antispasmodic agent and the QS supplement (as administered to treatment group D) previously has produced a significantly increased rate of ureteral stone expulsion. In all cases, U1 and U3, multivariate analysis with a Cox proportional hazards model indicated that the probability of expulsion was 2.183 times higher (95\% CI: 1.475 - 3.229), 2.403 times higher (95\% CI: $1.220-4.733)$ and 2.064 times higher $(95 \%$ CI: 1.249 - 3.409) in group $C$ than in group $B$, respectively. In all cases and U1 cases, the probability of expulsion was 1.962 times higher (95\% CI: 1.323 - 2.910) and 2.542 times higher (95\% CI: 1.298 - 4.979) in group D than in group B (Table 2).

Multivariate analysis with a Cox proportional hazards model indicated an increased probability of expulsion of stones measuring less than $6 \mathrm{~mm}$ (Table 3). In all cases, the probability of expulsion was 1.570 times higher (95\% CI: 1.039 - 2.374) in group $\mathrm{C}$ than in group A $(\mathrm{P}<0.05)$. In U3 cases, the probability of expulsion was 1.778 times higher $(95 \% \mathrm{CI}$ : 1.066 - 2.965) in group $\mathrm{C}$ than in group $\mathrm{A}(\mathrm{P}<0.05)$, while group $\mathrm{C}$ compared with group $\mathrm{B}$ demonstrated the probability of expulsion in all ureteral stone and U3 stone cases.

Multivariate analysis with a Cox proportional hazards 
Table 1. Patient Characteristics and Clinical Outcomes in the Four Treatment Groups

\begin{tabular}{|c|c|c|c|c|c|}
\hline & \multicolumn{4}{|c|}{ Group } & \multirow{3}{*}{ P value } \\
\hline & \multirow{2}{*}{ A } & \multirow{2}{*}{$\begin{array}{l}\text { B } \\
\text { Quercus salicina } \\
+ \text { flopropione }\end{array}$} & \multirow{2}{*}{$\begin{array}{l}\text { C } \\
\text { Naftopidil }\end{array}$} & \multirow{2}{*}{$\begin{array}{l}\text { D } \\
\text { Quercus salicina }+ \\
\text { flopropione + naftopidil }\end{array}$} & \\
\hline & & & & & \\
\hline Randomized patients (n) & 125 & 125 & 125 & 125 & \\
\hline Withdrawal patients (n) & 38 & 39 & 44 & 44 & \\
\hline Extracorporeal shock-wave lithotripsy & 12 & 13 & 15 & 14 & \\
\hline Ureteral stent & 5 & 6 & 7 & 6 & \\
\hline Hospital change & 1 & 0 & 1 & 2 & \\
\hline Treatment of other diseases & 1 & 1 & 1 & 1 & \\
\hline \multicolumn{6}{|l|}{ Stone location (n) } \\
\hline Right/left & $40 / 47$ & $33 / 53$ & $42 / 39$ & $33 / 48$ & NS \\
\hline Proximal & 27 & 42 & 33 & 33 & NS \\
\hline Middle & 6 & 6 & 5 & 4 & NS \\
\hline Distal & 54 & 38 & 43 & 44 & NS \\
\hline Duration of passage, days, mean (SD) & $20.0(9.8)$ & $22.6(9.3)$ & $16.8(9.9)^{*}$ & $17.8(10.3)$ & NS $* 0.040$ \\
\hline Proximal & $23.5(8.7)$ & $25.2(8.1)$ & $20.1(10.4)$ & $19.5(10.5)$ & NS \\
\hline Middle & $27.3(6.5)$ & $24.0(9.4)$ & $24.2(7.3)$ & $23.3(7.3)$ & NS \\
\hline Distal & $17.4(9.7)$ & $19.5(9.9)$ & $13.4(8.6)^{*}$ & $16.0(10.2)$ & $\mathrm{NS} * 0.041$ \\
\hline
\end{tabular}

The difference of each group compared with analgesic only group was shown in analyzed patients, patient age, stone size, stone location and duration of passage. *Analgesics only versus naftopidil group. NS: not significant; SD: standard deviation.

model indicated the probability of expulsion of stones measuring $6 \mathrm{~mm}$ or more (Table 4). None of the ureteral stones measuring $6 \mathrm{~mm}$ or more had facilitated spontaneous passage, while groups $\mathrm{C}$ and $\mathrm{D}$ compared with group B demonstrated the probability of expulsion in all ureteral stone cases.

\section{Discussion}

Spontaneous passage of ureteral stones less than $10 \mathrm{~mm}$ in longer diameter can be expected. Murakami et al reported that stones in the lower ureter more easily expel spontaneously; approximately $50 \%$ of lower ureteral stones are expelled spontaneously within 1 month after diagnosis and about $90 \%$ are expelled within 4 months [15]. Pain control and diuresis by drinking water are important for facilitating spontaneous passage of ureteral stones. Conservative therapy in Japan has commonly involved QS extract and flopropione with NSAIDs to reduce the ureteral spasms that induce stone stagnation, promote stone expulsion and alleviate renal colic.

QS extract has been clinically used in Japan since 1969 in the treatment of urolithiasis as an alternative medicine that facilitates the spontaneous expulsion of ureteral stones [16]. QS extract promotes stone discharge in a rat ureteral stone model [17], has a diuretic effect in urolithiasis patients [15], dissolves calcium phosphate crystals and prevents crystal growth at a silk thread nucleus in the rat bladder [18], and has an effect in preventing stone formation and recurrence in urolithiasis patients [19]. The stone composition in the four groups was mainly calcium oxalate or a mixture of calcium oxalate and calcium phosphate. Therefore, it is likely that there was little effect of the QS extract except on the stones containing calcium phosphate. The effect of flopropione as an antispasmodic agent on the rate of passing a calculus from the urinary tract has been compared retrospectively with patients in whom passage was spontaneous. Flopropione was shown to be superior to the control in cumulative passage rate after initiation of treatment [20]. Flopropione has been shown to exert a spasmolytic effect not only on smooth muscle of the gastrointestinal tract but also on smooth muscle of the pancreatobiliary and urinary systems [21].

It has been reported that $\alpha 1$-receptors exist not only at the edge of the ureter but also in the upper and medial ureter. Itoh et al evaluated the $\alpha 1 \mathrm{~A}-, \alpha 1 \mathrm{~B}-$ and $\alpha 1 \mathrm{D}$ - subtype mRNA with real-time reverse transcription polymerase chain reaction and immunohistochemical staining using ureteral specimens of 20 
Table 2. Cox Proportional Hazards Model: Multivariate Analysis for the Probability of Overall Stone Expulsion in Each Ureteral Position

\begin{tabular}{|c|c|c|c|}
\hline & Hazard ratio & $95 \%$ CI & P value \\
\hline \multicolumn{4}{|l|}{ Whole ureter } \\
\hline A vs. B & 0.638 & $0.429-0.948$ & 0.0262 \\
\hline A vs. C & 1.426 & $1.000-2.033$ & 0.0497 \\
\hline B vs. C & 2.183 & $1.475-3.229$ & $<0.0001$ \\
\hline A vs. D & 1.267 & $0.886-1.814$ & NS \\
\hline B vs. D & 1.962 & $1.323-2.910$ & 0.0008 \\
\hline \multicolumn{4}{|l|}{ Proximal } \\
\hline A vs. B & 0.766 & $0.348-1.687$ & NS \\
\hline A vs. C & 1.805 & $0.870-3.746$ & NS \\
\hline B vs. C & 2.403 & $1.220-4.733$ & 0.0113 \\
\hline A vs. D & 1.915 & $0.928-3.953$ & NS \\
\hline B vs. D & 2.542 & $1.298-4.979$ & 0.0065 \\
\hline \multicolumn{4}{|l|}{ Middle } \\
\hline A vs. B & 1.158 & $0.163-8.238$ & NS \\
\hline A vs. C & 2.259 & $0.371-13.76$ & NS \\
\hline B vs. C & 1.650 & $0.275-9.906$ & NS \\
\hline A vs. D & 3.283 & $0.523-20.60$ & NS \\
\hline B vs. D & 2.170 & $0.360-13.08$ & NS \\
\hline \multicolumn{4}{|l|}{ Distal } \\
\hline A vs. B & 0.708 & $0.437-1.146$ & NS \\
\hline A vs. C & 1.555 & $1.013-2.388$ & 0.0440 \\
\hline B vs. C & 2.064 & $1.249-3.409$ & 0.0047 \\
\hline A vs. D & 1.082 & $0.699-1.675$ & NS \\
\hline B vs. D & 1.494 & $0.901-2.478$ & NS \\
\hline
\end{tabular}

A: analgesics only. B: daily doses of $240 \mathrm{mg}$ flopropione and $1,350 \mathrm{mg}$ QS. C: daily dose of $50 \mathrm{mg}$ naftopidil. D: daily dose of $240 \mathrm{mg}$ flopropione, 1,350 mg QS and $50 \mathrm{mg}$ naftopidil. Cl: confidence interval; NS: not significant.

patients that underwent nephroureterectomy [5]. In the proximal and medial ureter, the distribution of $\alpha 1$-adrenoreceptors was $\alpha 1 \mathrm{D} \geq \alpha 1 \mathrm{~A}>\alpha 1 \mathrm{~B}$. In the distal ureter, the distribution of $\alpha 1$-adrenoreceptors was $\alpha 1 \mathrm{D}>\alpha 1 \mathrm{~A}>\alpha 1 \mathrm{~B}$. Sun et al reported that daily administration of $50 \mathrm{mg}$ naftopidil, a selective $\alpha 1 \mathrm{D}-$ blocker, increased the distal ureteral stone expulsion rate 5.263-fold compared to the control [6]. Ohgaki et al showed that $50 \mathrm{mg}$ naftopidil in combination with $240 \mathrm{mg}$ flopropione and $1,350 \mathrm{mg}$ QS extract once daily compared with 0.2 $\mathrm{mg}$ tamsulosin or $30 \mathrm{mg}$ urapidil with these drugs significantly increased the ureteral stone expulsion rate 2.38-fold compared to $240 \mathrm{mg}$ flopropione and $1,350 \mathrm{mg}$ QS extract once daily [12]. Kohjimoto et al showed that $75 \mathrm{mg}$ naftopidil once daily significantly increased distal ureteral stone expulsion rate to 1.78 times that of $240 \mathrm{mg}$ flopropione once daily [10]. The rationale for the administration of naftopidil in this study is that the $\alpha 1 \mathrm{D}$ receptor is widely distributed from the proximal to distal ureter [5].
Table 3. Cox Proportional Hazards Model: Multivariate Analysis for the Probability of Expulsion of Stones $<6 \mathrm{~mm}$ in Each Ureteral Position

\begin{tabular}{clll}
\hline & Hazard ratio & $\mathbf{9 5 \%}$ CI & P value \\
\hline Whole ureter & & & \\
A vs. B & 0.751 & $0.477-1.183$ & NS \\
A vs. C & 1.570 & $1.039-2.374$ & 0.0329 \\
B vs. C & 2.000 & $1.270-3.150$ & 0.0028 \\
A vs. D & 1.145 & $0.759-1.727$ & NS \\
B vs. D & 1.513 & $0.963-2.377$ & NS \\
Proximal & & & \\
A vs. B & 0.704 & $0.271-1.825$ & NS \\
A vs. C & 1.617 & $0.707-3.698$ & NS \\
B vs. C & 2.363 & $0.999-5.586$ & NS \\
A vs. D & 1.385 & $0.622-3.085$ & NS \\
B vs. D & 2.028 & $0.881-4.670$ & NS \\
Distal & & & \\
A vs. B & 0.775 & $0.453-1.328$ & NS \\
A vs. C & 1.778 & $1.066-2.965$ & 0.0275 \\
B vs. C & 2.105 & $1.190-3.724$ & 0.0105 \\
A vs. D & 1.115 & $0.672-1.849$ & NS \\
B vs. D & 1.396 & $0.793-2.456$ & NS \\
\hline
\end{tabular}

A: analgesics only. B: daily doses of $240 \mathrm{mg}$ flopropione and $1,350 \mathrm{mg}$ QS. C: daily dose of $50 \mathrm{mg}$ naftopidil. D: daily dose of $240 \mathrm{mg}$ flopropione, 1,350 mg QS and $50 \mathrm{mg}$ naftopidil. Cl: confidence interval; NS: not significant.

Anticholinergic (antimuscarinic) drugs are used in clinical urology to treat bladder motor hyperreflexia and renal or ureteral colic, based on the hypothesis that an antimuscarinic drug would decrease hypercontractility and spasms of the bladder and ureter. However, there is no preclinical evidence that the continuous use of anticholinergic medication for an extended period for bladder hyperreflexia results in upper urinary tract dilation, as shown in an animal model [22].

It has been reported that scopolamine treatment does not affect renal colic or spontaneous passage of stones; ureteral peristalsis did not increase even after scopolamine was injected intravenously [23].

For the whole range of ureteral stone types, the addition of naftopidil to flopropione and QS extract therapy was predicted to facilitate stone expulsion, as in the previous study. This study additionally includes a control (follow-up) group and naftopidil-alone group. The addition of naftopidil to flopropione and QS extract therapy significantly facilitated stone expulsion regardless of stone size. Flopropione and QS extract therapy compared with the control did not appear to facilitate stone expulsion. Naftopidil alone slightly facilitated stone expulsion compared to controls through the overall range of ureteral stones, U3 stones and overall ureteral stones less than $6 \mathrm{~mm}$. From these results, it appears that flopropione and QS extract therapy has a negligible effect on the overall probabil- 
Table 4. Cox Proportional Hazards Model: Multivariate Analysis for the Probability of Expulsion of Stones $>6 \mathrm{~mm}$ in Each Ureteral Position

\begin{tabular}{|clll}
\hline & Hazard ratio & $\mathbf{9 5 \%}$ CI & p value \\
\hline Whole ureter & & & \\
A vs. B & 0.514 & $0.228-1.159$ & NS \\
A vs. C & 1.345 & $0.662-2.732$ & NS \\
B vs. C & 2.621 & $1.197-5.735$ & 0.0159 \\
A vs. D & 1.518 & $0.732-3.148$ & NS \\
\hline B vs. D & 2.961 & $1.325-6.617$ & 0.0081 \\
Proximal & & & \\
A vs. B & 1.465 & $0.296-7.261$ & NS \\
A vs. C & 2.683 & $0.541-13.30$ & NS \\
\hline B vs. C & 1.894 & $0.610-5.881$ & NS \\
A vs. D & 2.855 & $0.521-15.64$ & NS \\
B vs. D & 2.007 & $0.565-7.133$ & NS \\
\hline Distal & & & \\
\hline A vs. B & 0.486 & $0.157-1.511$ & NS \\
A vs. C & 1.316 & $0.564-3.073$ & NS \\
B vs. C & 2.641 & $0.822-8.493$ & NS \\
A vs. D & 1.009 & $0.425-2.400$ & NS \\
B vs. D & 2.107 & $0.648-6.857$ & NS \\
\hline
\end{tabular}

A: analgesics only. B: daily doses of $240 \mathrm{mg}$ flopropione and $1,350 \mathrm{mg}$ QS. C: daily dose of $50 \mathrm{mg}$ naftopidil. D: daily dose of $240 \mathrm{mg}$ flopropione, 1,350 mg QS and $50 \mathrm{mg}$ naftopidil. Cl: confidence interval; NS: not significant.

ity of stone expulsion.

Evaluation according to location of the ureteral stones showed no effect of any treatment compared to controls for the middle and upper ureteral stones, and that naftopidil alone slightly promoted ureteral stone expulsion compared with controls for the lower ureteral stones. Naftopidil alone was effective in promoting smaller, lower ureteral stone expulsion, but all therapies were ineffective in overall upper ureteral stone or larger stone expulsion. The investigation of stone expulsion effect by ureteral stone size showed that naftopidil alone compared with the addition of naftopidil to flopropione and QS extract therapy significantly facilitated stone expulsion through the whole range of overall ureteral stones less than 6 $\mathrm{mm}$ (Table 3 ). There was no effect of any treatment compared to the control group through the whole range of overall ureteral stones of $6 \mathrm{~mm}$ and larger (Table 4). From these results, it appears that conventional treatment with anticholinergic agents may possibly retard stone expulsion.

Considering that no group was involved in promoting expulsion of larger stones, the involvement of $\alpha 1$ receptors may be limited in stone expulsion in the cases of ureteral stones 6 $\mathrm{mm}$ in size or larger. Neither $\alpha 1$ blockers nor other expulsive promoter drugs promote ureteral peristalsis; therefore, even though the $\alpha 1$ blocker is known to have a ureteral dilation effect, this may be the reason these therapies failed to promote stone expulsion.

For the whole range of ureteral stones, naftopidil alone, the addition of naftopidil to flopropione and QS extract therapy, and follow-up only facilitated stone expulsion compared with flopropione and QS extract therapy; ineffectiveness of stone expulsion by flopropione and QS extract was apparent. Further, compared to the control treatment with only NSAIDs and analgesics, the stone expulsion effect of naftopidil was not as high as expected. The role of flopropione and QS extract, which have been prescribed in Japan for many years, may need to be reconsidered for promoting stone expulsion. For relatively small lower ureteral stones, administration of naftopidil in addition to administration of NSAIDs for pain relief might be necessary. However, naftopidil might not be necessary for relatively large stones.

\section{Limitations}

A limitation of the present study was the unexpectedly high drop-out rate. However, I was still able to observe some effect of naftopidil as an MET. Also, the study included only male patients because of restrictions regarding the use of naftopidil in the Japanese insurance system. Although the number of patients enrolled was small, the results will be helpful to medical doctors considering naftopidil as an MET for patients with a ureter stone.

\section{Conclusions}

In MET, the need for antispasmodic agents is limited, as they appear to delay the excretion of ureteral stones. For relatively small ureteral stones, analgesic treatment combined with naftopidil would be the first choice. However, for relatively large ureteral stones, additional interventions for symptomatic patients would be necessary.

\section{Acknowledgments}

None to declare.

\section{Financial Disclosure}

No funding was received for the publication of this study.

\section{Conflict of Interest}

The author declares that there is no conflict of interest associated with the work described in the manuscript.

\section{Informed Consent}

All patients provided valid informed consent. 


\section{Author Contributions}

The author was involved in patient care and wrote or edited the manuscript.

\section{References}

1. Sakamoto S, Miyazawa K, Yasui T, Iguchi T, Fujita M, Nishimatsu H, Masaki T, et al. Chronological changes in the epidemiological characteristics of upper urinary tract urolithiasis in Japan. Int J Urol. 2018;25(4):373-378.

2. Dellabella M, Milanese G, Muzzonigro G. Efficacy of tamsulosin in the medical management of juxtavesical ureteral stones. J Urol. 2003;170(6 Pt 1):2202-2205.

3. Troxel SA, Jones AW, Magliola L, Benson JS. Physiologic effect of nifedipine and tamsulosin on contractility of distal ureter. J Endourol. 2006;20(8):565-568.

4. Yilmaz E, Batislam E, Basar MM, Tuglu D, Ferhat M, Basar $\mathrm{H}$. The comparison and efficacy of 3 different alpha1-adrenergic blockers for distal ureteral stones. J Urol. 2005;173(6):2010-2012.

5. Itoh Y, Kojima Y, Yasui T, Tozawa K, Sasaki S, Kohri K. Examination of alpha 1 adrenoceptor subtypes in the human ureter. Int J Urol. 2007;14(8):749-753.

6. Sun X, He L, Ge W, Lv J. Efficacy of selective alpha1Dblocker naftopidil as medical expulsive therapy for distal ureteral stones. J Urol. 2009;181(4):1716-1720.

7. Zhou SG, Lu JL, Hui JH. Comparing efficacy of alpha1Dreceptor antagonist naftopidil and alpha1A/D-receptor antagonist tamsulosin in management of distal ureteral stones. World J Urol. 2011;29(6):767-771.

8. Lu JL, Tang QL, De Liu F, Hui JH. Naftopidil and tolterodine in the medical expulsive therapy for intramural ureteral stones: a prospective randomized study. Urol Res. 2012;40(6):757-762.

9. Lv JL, Tang QL. Comparative evaluation of efficacy of use of naftopidil and/or celecoxib for medical treatment of distal ureteral stones. Urolithiasis. 2014;42(6):541-547.

10. Kohjimoto Y, Hagino K, Ogawa T, Inagaki T, Kitamura S, Nishihata M, Iba A, et al. Naftopidil versus flopropione as medical expulsive therapy for distal ureteral stones: results of a randomized, multicenter, double-blind, controlled trial. World J Urol. 2015;33(12):2125-2129.

11. Li J, Tang Z, Gao L, Li J, Qin F, Yuan J. Efficacy and safety of naftopidil in the medical expulsion therapy for distal ureteral stone: a systematic review and meta-analysis. J Endourol. 2017;31(5):427-437.

12. Ohgaki K, Horiuchi K, Hikima N, Kondo Y. Facilitation of expulsion of ureteral stones by addition of alpha1blockers to conservative therapy. Scand J Urol Nephrol. 2010;44(6):420-424.

13. Cho SY, Na W, Lee SW, Cho MC, Oh JJ, Lee S, Park J, et al. Medical expulsive therapy for ureter stone using naftopidil: A multicenter, randomized, double-blind, and placebo-controlled trial. PLoS One. 2017;12(4):e0174962.

14. Kanda Y. Investigation of the freely available easy-touse software 'EZR' for medical statistics. Bone Marrow Transplant. 2013;48(3):452-458.

15. Murakami M, Yamaguchi K, Mori I, Naito H, Miyauchi T, Ito H, Shimazaki J. [Clinical statistics on urolithiasis]. Nihon Hinyokika Gakkai Zasshi. 1982;73(11):13951401.

16. Ishigami J, Ooshima H, Saitou H. Clinical effect of UROCALUN on urolithiasis in the upper urinary tract. Hifu to Hinyo. 1967;29:858-862 (In Japanese).

17. Natsukawa T, Hirata K, Noda K, Oka M, Tanaka M, Hamada K. Promoting effect of extract of Quercus salicina Blume/Q. stenophylla Makino (UROCALUN) on urinary stone passage. Jpn Pharmacol Ther. 2005;33:361368 (In Japanese).

18. Ookita K, Yamada S, Johsen T, Tanaka M. Uses of UC-2 for treatment of upper urinary calculi and studies on dissolution of urinary calculi by UC-2. Hifu to Hinyo. 1967;30:426-431 (In Japanese).

19. Moriyama MT, Suga K, Miyazawa K, Tanaka T, Higashioka M, Noda K, Oka M, et al. Inhibitions of urinary oxidative stress and renal calcium level by an extract of Quercus salicina Blume/Quercus stenophylla Makino in a rat calcium oxalate urolithiasis model. Int J Urol. 2009;16(4):397-401.

20. Murata S, Ooe H, Mishina T, Mori Y, Tanaka S. Medical Treatment of ureteral stones - clinical evaluation of cospanon. Nishinippon J Urol. 1975;37:157-159 (In Japanese).

21. Ichikawa S, Yaegashi T. [Effects of 2,4,6-trihydroxypropiophenone on the motility of bile duct and ureter]. Nihon Heikatsukin Gakkai Zasshi. 1968;4(2):151-159.

22. Roshani H, Dabhoiwala NF, Dijkhuis T, Pfaffendorf M, Boon TA, Lamers WH. Pharmacological modulation of ureteral peristalsis in a chronically instrumented conscious pig model. I: Effect of cholinergic stimulation and inhibition. J Urol. 2003;170(1):264-267.

23. Becker AJ, Stief CG, Meyer M, Truss MC, Forssmann WG, Jonas U. The effect of the specific phosphodiesterase-IV-inhibitor rolipram on the ureteral peristalsis of the rabbit in vitro and in vivo. J Urol. 1998;160(3 Pt 1):920925 . 